\title{
Aberrant methylation of yes-associated protein (YAP1) as a potential biomarker in breast cancer
}

\author{
Ragaa Abdelkader Ramadan ${ }^{1 *} \mathbb{D}$, Ahmed Elkarmouty ${ }^{2}$ and Mostafa Elnaggar ${ }^{3}$
}

\begin{abstract}
Background: Breast cancer (BC) represents the most prevalent malignancy among women, and it is characterized by high mortality especially in late stages. BC tumorigenesis was linked to epigenetic alterations namely methylation. Yesassociated protein (YAP1) is the leading downstream effector of the Hippo pathway. It may enhance or inhibit oncogenesis based on the tissue involved.

Aim: This case-control study aimed to analyze the methylation degree of promoter region of YAP1 gene in BC patients by applying methylation-specific polymerase chain reaction (MSP) analysis.

Methods: Genomic deoxyribonucleic acid (DNA) was isolated from 50 paired tumor and adjacent noncancerous breast tissue samples and subjected to bisulfite conversion. Methylation condition of YAP1 gene was studied by MSP and evaluated as a possible biomarker for diagnosing $\mathrm{BC}$ and its differentiation from corresponding normal tissues. We also correlated the aberrant methylation with clinicopathological criteria.

Results: Increased methylation of the YAP1 gene promoter region in BC tumor tissue was detected in $68 \%$ of the studied BC tissue samples. There was a significant change in the frequency of YAP1 methylated genotype between breast tumor tissues compared to that in adjacent non-cancerous tissue $(p<0.001)$. YAP1 can discriminate early from late-stage BC with a sensitivity of $96.88 \%$ and specificity of $83.33 \%$.
\end{abstract}

Conclusions: Gene analysis of YAP1 using conventional MSP in tissue specimens can be considered a possible biomarker to distinguish BC from normal breast tissue as well as between early- and late-stage BC.

Keywords: Breast cancer, Hippo pathway, Methylation-specific polymerase chain reaction analysis, Yes-associated protein (YAP1)

\section{Background}

Breast cancer (BC) is considered the most common malignancy in females, and it accounts for approximately $32.04 \%$ of the reported cancers in Egyptian women [1]. Cancer biomarkers' research has shown that not only genetic mutations, but also epigenetic alterations such as promoter methylation patterns have potential value in early recognition of malignant growth. Silencing of tumor suppressor genes through hypermethylation and activation of oncogenes by

\footnotetext{
* Correspondence: ragaa.abdelkader@gmail.com

'Department of Chemical Pathology, Medical Research Institute, Alexandria University, 165 Horreya Avenue, Hadara, POB: 21561, Alexandria, Egypt Full list of author information is available at the end of the article
}

hypomethylation are hallmarks of early molecular epimarkers in BC development [2].

Mounting evidence emphasizes the significance of DNA methylation, not only for being potentially modifiable but also because it is related to age, the strongest $\mathrm{BC}$ risk predictor [3]. The Cancer Genome Atlas studied the whole genome methylation of more than 10,000 human samples from more than 30 distinct tumors and paired normal controls [4]. With the accessibility of such immense amount of genetic data, the challenge is to capture the most significant genes with relevance to diagnosis and personalized medicine.

One of the most frequent epigenetic alterations described is increased methylation of breast cancer gene (BRCA1). By using peripheral blood, BRAC1 promoter 
methylation could serve as a screening tool as well as predictive biomarker for poly ADP ribose polymerase (PARP1) inhibitor therapy, which has been used for management of BRCA1 and BRCA2 mutations to reduce tumor growth and vascularization $[5,6]$.

Yes-associated protein $(Y A P)$ gene is mapped to chromosome region 11q22 amplicon [7]. YAP1 is considered a specific transcriptional activator and a leading effector of the Hippo tumor suppressor pathway. The Hippo pathway is an evolutionarily conserved kinase cascade which is implicated in cell proliferation, organ development, regeneration, and stem cell biology. YAP1 regulates nuclear cellular responses by interacting with transcription factors. It also modulates actin filament architecture and cell migration $[8,9]$.

Hippo pathway is inhibited by distinct signaling pathways, and this causes hyperactivation of YAP1 with its subsequent shift to the nucleus. The hyperactivated YAP1 interacts with transcription regulators such as TEA domain/Transcription Enhancer Factor (TEAD) family. The complex between YAP1 and TEAD molecules is crucial for growth-enhancing function of YAP1 [10]. The mechanism by which YAP1 performs its tumor suppressor or oncogenic functions is not yet completely understood.

\section{Aim}

Regarding the aforementioned points, study of DNA methylation seems to be important in developing new diagnostic biomarkers; therefore, this work aimed at analyzing the methylation profile of $Y A P 1$ in $\mathrm{BC}$ patients using MSP analysis. Furthermore, the correlation of clinicopathological parameters and aberrant methylation was examined.

\section{Methods}

Fifty females, genetically unrelated, with primary BC undergoing breast surgery at the Medical Research Institute Teaching Hospital, Alexandria, Egypt, during the period 2016-2017, were included in our study. BC was diagnosed according to standard clinical, radiological, and histological parameters. Patients were subjected to thorough physical examinations, chest radiography, bilateral mammography, and ultrasonography of the breasts, axilla, cervical region, and abdomen before surgical resection. Breast tumor tissue and normal adjacent breast tissue not infiltrated with tumor, serving as control, were obtained from subjects during surgery. Exclusion criteria were previous exposure to neoadjuvant chemotherapy, radiotherapy, or hormonal therapy. Patients with multiple cancers and patients with acute myocardial or surgical complications were excluded. The tumor histological types, grading, and TNM staging were assessed [11]. Late stage was defined as stage III and stage IV. The study was approved by the Ethical Committee of Medical Research Institute, Alexandria University (IORG\#: IORG008812). All subjects have signed the informed consent and agreed the research purposes of clinical data and samples of our study. Postoperative pathology examination, as well as hormonal receptors (ER and PR) and epidermal growth factor receptor 2(HER-2), was done by immunohistochemistry [12].

\section{DNA extraction and sodium bisulfite modification}

Briefly, extraction of genomic deoxyribonucleic acid (DNA) from breast tumor and adjacent normal breast tissue was done using the Gene JET ${ }^{\mathrm{rm}}$ Genomic DNA Purification Kit (Thermo Fisher Scientific) according to the manufacturer's instructions. The isolated DNA was evaluated by Nanodrop ND 1000 spectrophotometer (Thermo Scientific, USA) and confirmed by gel electrophoresis running. The ratio of absorbance at $260 \mathrm{~nm}$ and $280 \mathrm{~nm}$ (A260/A280) was taken to assess the purity of the DNA.

Bisulfite conversion for the extracted DNA was done using the EZ DNA Methylation ${ }^{\mathrm{Tm}}$ Kit (Zymo Research Corp) according to the manufacturer's instructions. Treatment of DNA with sodium bisulfite converted unmethylated cytosines into uracil, while methylated cytosines remained unchanged. Bisulfite modification step creates sequence differences in the DNA. The converted DNA was then stored at $-20^{\circ} \mathrm{C}$ till use. MSP was carried out according to the method described earlier by Herman et al. [13] and performed previously by the author Ramadan et al. [14]. Separate MSP reactions were carried out for both methylated and unmethylated DNA sequences utilizing primer sets specific for each reaction.

The primers used for amplification were:

\section{Forward: 5' -AGTTCGTATAGGCGTTTCGTTC-3' (methylated), F 5'-AAGTTTGTATAGGTGTTT \\ TGTTTGG-3 (unmethylated). \\ Backward: F 5'-CTTAACTACAAAAAATTC \\ TTCCGCT-3' (methylated), F 5'-CTTAACTACAAA \\ AAATTCTTCCACT-3' (unmethylated) [15]}

PCR was done by using a total volume of $25 \mu \mathrm{l}(12.5 \mu \mathrm{l}$ of ZymoTaq ${ }^{\text {ma }}$ PreMix, $5 \mu$ l of modified bisulfate DNA, $1 \mu \mathrm{l}$ of each primer, $5.5 \mu \mathrm{l}$ of nuclease-free $\mathrm{H} 2 \mathrm{O}$ ). The PCR reaction was performed using thermocycler (Quanta Biotech, UK) under the following conditions: initial denaturation at $95^{\circ} \mathrm{C}$ for $10 \mathrm{~min}$ followed by 35 cycles with denaturation at $95^{\circ} \mathrm{C}$ for $45 \mathrm{~s}$, annealing at $57^{\circ} \mathrm{C}$ for $30 \mathrm{~s}$, and extension at $72^{\circ} \mathrm{C}$ for $45 \mathrm{~s}$, and finally extension at $72{ }^{\circ} \mathrm{C}$ for $7 \mathrm{~min}$. The resultant PCR products were identified by electrophoresis on $2 \%$ agarose gel and 
stained with ethidium bromide for visualization under UV light.

With each run, positive and negative controls were incorporated. Completely unmethylated and methylated human genomic DNA (EpiTect Control DNA (human); Qiagen) were applied respectively for unmethylation- and methylation-positive control, while nuclease-free sterile water and non-bisulfite-modified DNA were employed as negative control. The PCR generated a 188-bp products for both methylated and unmethylated DNA.

Amplification was successful if a band appeared with the same size as that of the control $(100 \mathrm{bp})$. If amplification was successful in the unmethylated run and failed in the methylated run, this was considered as the unmethylated status (UU genotype) of the YAP1 promoter. If the reverse occurred (successful amplification in the methylated run and failed in the unmethylated run), that was hypermethylation (MM genotype). A successful amplification in both runs denoted hemimethylation (MU genotype), and this could suggest methylation heterogeneity where methylation is not inclusive of all $\mathrm{CpG}$ sites between the primers, hereby allowing amplification with both primer sets. An aberrant methylation was considered in hypermethylation and hemimethylation situations. All tissue samples were processed and analyzed in a blinded manner. Methylation status was further correlated with clinicopathological criteria.

\section{Statistics}

We compared YAP1 methylation frequency in tumor and non-tumor breast tissue. MSP results were analyzed as a dichotomous variable based on the occurrence of methylation. The methylation status of YAP1 and clinicopathological data were analyzed with the Pearson chi-square test, Fisher's exact test, and Monte Carlo test. The diagnostic performance of YAP1 methylation was evaluated. SPSS version 20 was applied, and a $p$ value $<0.05$ was considered statistically significant. Each $p$ value was statistically adjusted with the Bonferroni correction.

\section{Results}

The study included 50 paired tumor and adjacent normal breast tissues. The participants had a mean age of $46.6 \pm 8.45$ years. The demographic, biochemical, and clinical parameters of the participants are indicated in Table 1.

Promoter aberrant methylation of the YAP1 gene in $\mathrm{BC}$ tumor tissue was found in 34 of 50 (68\%), while adjacent normal tissue showed methylation in 4 of $50(8 \%)$. The frequency of methylation of the YAP1 gene was significantly higher in $\mathrm{BC}$ tissue compared to normal breast tissue with $(p<0.001)$.

The analytic results of the correlation between clinicopathological characteristics and methylation status of $Y A P 1$ gene showed that the aberrant methylation pattern was independent of the age, body mass index, menopausal status, histopathological type, tumor size, axillary lymph node involvement, and serum CA15-3 $(p>0.05)$. However, methylation status was significantly correlated with tumor stage $(p<0.001)$ (Table 1$)$. YAP1 methylation showed high accuracy (92\%) in discriminating between early and late BC (stage II vs stages II and IV) (Table 2). Although methylation status was significantly correlated with metastasis $(p=0.02)$, it showed low accuracy (52\%) in distinguishing those with and without metastasis (Table 3).

\section{Discussion}

It is known that YAP1 regulates the downstream effect of Hippo signaling. YAP1 regulates organ size by controlling cellular proliferation and survival. Kinasemediated phosphorylation of YAP1 promotes its sequestration from the nucleus to the cytoplasm, with subsequent downregulation of its target genes $[8,9]$.

In the present study, we investigated the usefulness of $Y A P 1$ as a biomarker in BC. Our results demonstrated that $Y A P 1$ methylation was significantly higher in $\mathrm{BC}$ tissue compared to normal breast tissue and showed a significant correlation with tumor stage. Moreover, the methylation status had good diagnostic performance (accuracy of 92\%) in differentiating between early and late stages. Although methylation profile was significantly associated with metastasis and showed 100\% sensitivity and negative predictive value, the specificity and positive predictive value were low. This may be attributed to the relatively small percent (10 cases) of participants with metastasis.

The relation of YAP1 with BC was previously examined by immunohistochemical assay, Western blotting, and by real-time quantitative PCR. Different expression levels as well as different subcellular localization were observed [16-19]. The general conclusion of several reports was the association of dysregulation of YAP1 with tumor aggressiveness in $B C[20,21]$.

In accordance with our findings, Real et al., by using MSP, reported methylation in $70.8 \%$ of the studied BC tissue samples. They found a significantly high correlation between YAP hypermethylation and YAP immunohistochemical expression. Although $84.13 \%$ cases of advanced BC stages III and IV had YAP promoter methylation and subsequent protein loss, they did not prove any significant association between YAP methylation and clinicopathological criteria [15]. 
Table 1 Correlation analysis of YAP1 promoter methylation with different variables

\begin{tabular}{|c|c|c|c|c|c|}
\hline Variable & $\begin{array}{l}\text { Total } \\
n(\%)\end{array}$ & $\begin{array}{l}\text { Unmethylated } \\
N=16(\%)\end{array}$ & $\begin{array}{l}\text { Methylated } \\
N=34(\%)\end{array}$ & Test of Significance & $p$ value \\
\hline \multicolumn{6}{|l|}{ Age (years) } \\
\hline$\leq 50$ & $31(62)$ & $12(38.7)$ & $19(61.3)$ & \multirow[t]{2}{*}{$x^{2}=1.688$} & \multirow[t]{2}{*}{0.194} \\
\hline$>50$ & $19(38)$ & $4(21.1)$ & $15(78.9)$ & & \\
\hline \multicolumn{6}{|l|}{ BMI $\left(\mathrm{kg} / \mathrm{m}^{2}\right)$} \\
\hline$\leq 25$ & $14(28)$ & $6(42.9)$ & $8(57.1)$ & \multirow[t]{2}{*}{$x^{2}=1.053$} & \multirow[t]{2}{*}{$\mathrm{FE}_{p}=0.330$} \\
\hline$>25$ & $36(72)$ & $10(27.8)$ & $26(72.2)$ & & \\
\hline \multicolumn{6}{|l|}{ Menopausal state } \\
\hline Premenopausal & $17(34)$ & $4(23.5)$ & $13(76.5)$ & \multirow[t]{2}{*}{$x^{2}=0.849$} & \multirow[t]{2}{*}{0.357} \\
\hline Postmenopausal & $33(66)$ & $12(36.4)$ & $21(63.6)$ & & \\
\hline \multicolumn{6}{|l|}{ Histopathological type } \\
\hline Ductal & $34(68)$ & $12(35.3)$ & $22(64.7)$ & \multirow[t]{3}{*}{$x^{2}=0.534$} & \multirow[t]{3}{*}{${ }^{M C} C_{p}=0.884$} \\
\hline Lobular & $12(24)$ & $3(25)$ & $9(75)$ & & \\
\hline Others & $4(8)$ & $1(25)$ & $3(75)$ & & \\
\hline \multicolumn{6}{|l|}{ Tumor stage } \\
\hline 1 & & & & \multirow[t]{4}{*}{$x^{2}=34.124^{*}$} & \multirow[t]{4}{*}{$<0.001^{*}$} \\
\hline$\|$ & $18(36)$ & $15(83.3)$ & $3(16.7)$ & & \\
\hline III & $22(44)$ & $1(4.5)$ & $21(95.5)$ & & \\
\hline IV & $10(20)$ & $0(0)$ & $10(100)$ & & \\
\hline \multicolumn{6}{|l|}{ Tumor size } \\
\hline$\leq 2 \mathrm{~cm}$ & $3(6)$ & $2(66.7)$ & $1(33.3)$ & \multirow[t]{2}{*}{$x^{2}=1.763$} & \multirow[t]{2}{*}{$\mathrm{FE}_{p}=0.237$} \\
\hline$>2 \mathrm{~cm}$ & $47(94)$ & $14(29.8)$ & $33(70.2)$ & & \\
\hline \multicolumn{6}{|c|}{ Axillary lymph node involvement } \\
\hline Yes & $47(94)$ & $14(29.8)$ & $33(70.2)$ & \multirow[t]{3}{*}{$x^{2}=1.763$} & \multirow[t]{3}{*}{${ }^{\mathrm{FE}} p=0.237$} \\
\hline No & $3(6)$ & $2(66.7)$ & $1(33.3)$ & & \\
\hline No & $40(80)$ & $16(40)$ & $24(60)$ & & \\
\hline \multicolumn{6}{|c|}{ Estrogen receptor status (ER) } \\
\hline Positive & $42(84)$ & $13(31)$ & $29(69)$ & \multirow[t]{2}{*}{$x^{2}=0.132$} & \multirow[t]{2}{*}{${ }^{\mathrm{FE}} p=0.699$} \\
\hline Negative & $8(16)$ & $3(37.5)$ & $5(62.5)$ & & \\
\hline \multicolumn{6}{|c|}{ Progesterone receptor status (PR) } \\
\hline Positive & $43(86)$ & $14(32.6)$ & $29(67.4)$ & \multirow[t]{2}{*}{$x^{2}=0.044$} & \multirow[t]{2}{*}{${ }^{\mathrm{FE}} p=1.000$} \\
\hline Negative & $7(14)$ & $2(28.6)$ & $5(71.4)$ & & \\
\hline HER2 expression status & & & & & \\
\hline Overexpression & $16(32)$ & $2(12.5)$ & $14(87.5)$ & $x^{2}=4.112^{*}$ & $0.043^{*}$ \\
\hline Non-overexpression & $34(68)$ & $14(41.2)$ & $20(58.5)$ & & \\
\hline CA15-3 (U/ml) & & & & & \\
\hline Mean \pm SD & $37.49 \pm 28.17$ & $28.78 \pm 12.94$ & $41.59 \pm 32.37$ & $t=1.520$ & 0.135 \\
\hline Median (min-max) & $34(11-190)$ & & & & \\
\hline
\end{tabular}

$x^{2}$ chi-square test, FE Fisher's exact, MC Monte Carlo, $t$ Student's $t$ test, $p p$ value for comparing between the two groups

*Statistically significant at $p \leq 0.05$

The function of YAP1 on being a tumor suppressor or oncogene is quite controversial. Overexpression of $Y A P 1$ was observed in lung [22], esophageal [23], and ovarian tumors [24]. The assumption that YAP1 may act as a tumor suppressor was based on the finding that human
$\mathrm{BC}$ tissue exhibits decreased YAP1 expression compared with normal breast tissue [17]. Moreover, knockdown of $Y A P 1$ in $\mathrm{BC}$ cell line and in mouse model demonstrated increased cellular migration and tumor invasiveness [25]. On the contrary, other studies advocated the oncogenic 
Table 2 Diagnostic performance of methylation to differentiate early and late tumor stages

\begin{tabular}{|c|c|c|c|c|c|c|c|c|c|}
\hline & \multicolumn{4}{|c|}{ Tumor stage } & \multirow[t]{3}{*}{ Sensitivity } & \multirow[t]{3}{*}{ Specificity } & \multirow[t]{3}{*}{ PPV } & \multirow[t]{3}{*}{ NPV } & \multirow[t]{3}{*}{ Accuracy } \\
\hline & \multicolumn{2}{|c|}{ Early $(n=18)$} & \multicolumn{2}{|c|}{ Late $(n=32)$} & & & & & \\
\hline & $n$ & $\%$ & $\mathrm{n}$ & $\%$ & & & & & \\
\hline \multicolumn{10}{|l|}{ Methylation } \\
\hline Unmethylated & 15 & 83.3 & 1 & 3.1 & 96.88 & 83.33 & 91.18 & 93.75 & 92.0 \\
\hline Methylated & 3 & 16.7 & 31 & 96.9 & & & & & \\
\hline$x^{2}(p)$ & \multicolumn{4}{|c|}{$34.059^{*}\left(<0.001^{*}\right)$} & & & & & \\
\hline
\end{tabular}

$X^{2}$ chi-square test, $P P V$ positive predictive value, NPV negative predictive value

*Statistically significant at $p \leq 0.05$

potentials of YAP1, since its overexpression in BC cell line [26] and in mice xenografts [18] increased proliferation and tumorigenesis.

Numerous mechanisms were postulated to explain the relation with $\mathrm{BC}$ tumorigenesis. One of which was reported by Shen et al. [27]; their findings showed that YAP1 enhanced tumor invasiveness by modulating thrombospondin 1 transcription, thus leading to focal adhesion kinase phosphorylation in a TEAD-dependent manner. Wang et al. showed that YAP1 promotes metastasis of $\mathrm{BC}$ by inhibiting the transcription of growth differentiation factor-15 which is a divergent element in the transforming growth factor superfamily [21].

We studied the relation of YAP1 methylation with the expression of hormone receptors, and we found a mild significant association with HER2 expression $(p=0.043)$, but no association was observed with ER or PR status. On the other hand, Kim et al. [28] reported that hyper-activation of YAP1 in $\mathrm{BC}$ tissues was associated directly to the PR status and inversely to HER2 and Ki67 levels. Others described the relation between reduced YAP1 expression and decreased recurrence-free survival in luminal cancers [20, 29]. This emphasizes the assumption that, at least in triple-negative BC, YAP1 may possess an oncogenic character. It is plausible that YAP1 acts differently in distinct $\mathrm{BC}$ subtypes.

Many laboratory methodologies exist for DNA methylation determination. However, the majority of the methods depend on bisulfite conversion of DNA. Then, the modified DNA is subsequently incorporated to additional molecular techniques; PCR, microarray technology, mass spectrometry or next-generation sequencing. The choice of the appropriate analytical methodology depends on the nature and number of the samples, information required, and cost. MSP is considered a quite sensitive and cost-effective tool without the need for expensive instruments, thus making it applicable to most clinical laboratories [2].

Based on the association of YAP1 with cancer proliferation and drug resistance, there were several trials to identify therapeutic small molecule inhibitors of YAP1 [30, 31]. Verteporfin (VP), a FDA-approved photosensitizing agent used in treatment of neo-vascular macular degeneration, blocks YAP-TEAD binding. LiuChittenden et al reported thatVP inhibited liver overgrowth resulting from the overexpression of YAP1 by silencing Hippo kinase components [32]. Surprisingly, statins were reported to have inhibitory effects on YAP1 by promoting its cytoplasmic sequestration and degradation [33]. Studies in animal models of cancers indicate that statins have tumor suppressor effects. This was ascertained in clinical studies showing the negative association of statins with cancer occurrence or survival [34].

Certain points are worth mentioning such as the selection of $\mathrm{CpG}$ containing regions with respect to differences observed in methylation levels of different locations. Further large-scale studies on different population in addition to validation with different methods,

Table 3 Diagnostic performance of methylation in relation to metastasis

\begin{tabular}{|c|c|c|c|c|c|c|c|c|c|}
\hline & \multicolumn{4}{|c|}{ Metastasis } & \multirow[t]{3}{*}{ Sensitivity } & \multirow[t]{3}{*}{ Specificity } & \multirow[t]{3}{*}{ PPV } & \multirow[t]{3}{*}{ NPV } & \multirow[t]{3}{*}{ Accuracy } \\
\hline & \multicolumn{2}{|c|}{ No metastasis $(n=40)$} & \multicolumn{2}{|c|}{ Metastasis $(n=10)$} & & & & & \\
\hline & $\mathrm{n}$ & $\%$ & $\mathrm{n}$ & $\%$ & & & & & \\
\hline \multicolumn{10}{|l|}{ Methylation } \\
\hline Unmethylated & 16 & 40.0 & 0 & 0.0 & 100.0 & 40.0 & 29.41 & 100.0 & 52.0 \\
\hline Methylated & 24 & 60.0 & 10 & 100.0 & & & & & \\
\hline$x^{2}(\mathrm{FE} p)$ & \multicolumn{4}{|c|}{$5.882^{*}\left(0.020^{*}\right)$} & & & & & \\
\hline
\end{tabular}

FE Fisher's exact test, $P P V$ positive predictive value, NPV negative predictive value

*Statistically significant at $p \leq 0.05$ 
and functional analyses of methylation profile are required in order to determine if the specific methylation patterns are exclusively associated with BC.

\section{Conclusion}

YAP1 methylation was significantly higher in $\mathrm{BC}$ tissue compared to normal breast tissue and showed a significant correlation with tumor stage. Moreover, the methylation status had good diagnostic performance in discriminating early and late stages. Our study pinpoints the value of promoter methylation of YAP1 in BC particularly in view of its future therapeutic potentials.

\section{Abbreviations}

BC: Breast cancer; BRCA1: Breast cancer gene; DNA: Deoxyribonucleic acid; MSP: Methylation-specific polymerase chain reaction; PARP: Poly ADP ribose polymerase; TEAD: TEA domain/Transcription Enhancer Factor; VP: Verteporfin; YAP: Yes-associated protein

\section{Acknowledgements}

Not applicable.

\section{Authors' contributions}

Author RR conceived of the presented idea. Authors RR and EA developed the study design and criteria of participants' selection. Authors EA and EM collected the specimens. Author RR performed the genetic analysis. All authors performed the statistical analysis, discussed the results, and contributed to the final manuscript. All authors read and approved the final manuscript.

\section{Funding}

No funding was obtained for this study.

\section{Availability of data and materials}

Data are presented in the main paper.

\section{Ethics approval and consent to participate}

The study was approved by the Ethical Committee of Medical Research Institute, Alexandria University (IORG\#: IORG008812). All subjects have signed informed written consent and agreed on the research purposes of clinical data and samples of our study.

\section{Consent for publication}

Not applicable.

\section{Competing interests}

The authors declare that they have no competing interests.

\section{Author details}

${ }^{1}$ Department of Chemical Pathology, Medical Research Institute, Alexandria University, 165 Horreya Avenue, Hadara, POB: 21561, Alexandria, Egypt. ${ }^{2}$ Department of Experimental and Clinical Surgery, Medical Research Institute, Alexandria University, Alexandria, Egypt. ${ }^{3}$ Department of Cancer Management and Research, Medical Research Institute, Alexandria University, Alexandria, Egypt.

Received: 15 May 2019 Accepted: 28 October 2019 Published online: 20 November 2019

\section{References}

1. Ibrahim AS, Khaled HM, Mikhail NN, Baraka H, Kamel H (2014) Cancer incidence in Egypt: results of the national population-based cancer registry program. J Cancer Epidemiol 2014:437971

2. Paska AV, Hudler P (2015) Aberrant methylation patterns in cancer: a clinical view. Biochem Med (Zagreb) 25:161-176

3. Horvath S, Zhang Y, Langfelder P, Kahn RS, Boks MP, van Eijk K et al (2012) Aging effects on DNA methylation modules in human brain and blood tissue. Genome Biol 13:R97
4. Marzese DM, Hoon DS (2015) Emerging technologies for studying DNA methylation for the molecular diagnosis of cancer. Expert Rev Mol Diagn 15: 647-664

5. Wong EM, Southey MC, Fox SB, Brown MA, Dowty JG, Jenkins MA et al (2011) Constitutional methylation of the BRCA1 promoter is specifically associated with BRCA1 mutation associated pathology in early-onset breast cancer. Cancer Prev Res 4:23-33

6. Cai F, Ge I, Wang M, Biskup E, Lin X, Zhong X (2014) Pyrosequencing analysis of BRCA1 methylation level in breast cancer cells. Tumour Biol 35: 3839-3844

7. Overholtzer M, Zhang J, Smolen GA, Muir B, Li W, Sgroi DC et al (2006) Transforming properties of YAP, a candidate oncogene on the chromosome 11q22 amplicon. Proc Natl Acad Sci U S A 103:12405-12410

8. Moroishi T, Hansen CG, Guan KL (2015) The emerging roles of YAP and TAZ in cancer. Nat Rev Cancer 15:73-79

9. Totaro A, Panciera T, Piccolo S (2018) YAP/TAZ upstream signals and downstream responses. Nat Cell Biol 20:888-899

10. Hansen CG, Moroishi T, Guan KL (2015) YAP and TAZ: a nexus for Hippo signaling and beyond. Trends Cell Biol 25:499-513

11. Greene FL, Page DL, Fleming ID (eds) (2002) AJCC cancer staging manual, 6th edn, p 435

12. Gown AM (2008) Current issues in ER and HER2 testing by IHC in breast cancer. Mod Pathol 21:S8-S15

13. Herman JG, Graff JR, Myöhänen S, Nelkin BD, Baylin SB (1996) Methylation specific PCR: a novel PCR assay for methylation status of CpG islands. Proc Natl Acad Sci U S A 93:9821-9826

14. Ramadan RA, Zaki MA, Awad AM, El-Ghalid LA (2015) Aberrant methylation of promoter region of SPINT2/HAl-2 gene: an epigenetic mechanism in hepatitis C virus-induced hepatocarcinogenesis. Genet Test Mol Biomarkers 19:399-404

15. Real SAS, Parveen F, Rehman AU, Khan MA, Deo SVS, Shukla NK et al (2018) Aberrant promoter methylation of YAP gene and its subsequent downregulation in Indian breast cancer patients. BMC Cancer 18:711

16. Zhao B, Tumaneng K, Guan KL (2011) The Hippo pathway in organ size control, tissue regeneration and stem cell self-renewal. Nat Cell Biol 13:877-883

17. Tufail R, Jorda M, Zhao W, Reis I, Nawaz Z (2012) Loss of yes-associated protein (YAP) expression is associated with estrogen and progesterone receptor negativity in invasive breast carcinomas. Breast Cancer Res Treat 131:743-750

18. Wang X, Su L, Ou Q (2012) Yes-associated protein promotes tumour development in luminal epithelial derived breast cancer. Eur J Cancer 48: $1227-1234$

19. Kim SK, Jung WH, Koo JS (2014) Yes-associated protein (YAP) is differentially expressed in tumor and stroma according to the molecular subtype of breast cancer. Int J Clin Exp Pathol 7:3224-3234

20. Kim HM, Jung WH, Koo JS (2015) Expression of yes-associated protein (YAP) in metastatic breast cancer. Int J Clin Exp Pathol 8:11248-11257

21. Wang T, Mao B, Cheng C, Zou Z, Gao J, Yang Y et al (1864) YAP promotes breast cancer metastasis by repressing growth differentiation factor-15. Biochim Biophys Acta 2018:1744-1753

22. Wang Y, Dong Q, Zhang Q, Li Z, Wang E, Qiu X (2010) Overexpression of yes-associated protein contributes to progression and poor prognosis of non-small-cell lung cancer. Cancer Sci 101:1279-1285

23. Muramatsu T, Imoto I, Matsui T, Kozaki K, Haruki S, Sudol M et al (2011) YAP is a candidate oncogene for esophageal squamous cell carcinoma. Carcinogenesis 32:389-398

24. Zhang X, George J, Deb S, Degoutin JL, Takano EA, Fox SB et al (2011) The Hippo pathway transcriptional co-activator, YAP, is an ovarian cancer oncogene. Oncogene 30:2810-2822

25. Yuan M, Tomlinson V, Lara R, Holliday D, Chelala C, Harada T et al (2008) Yes-associated protein (YAP) functions as a tumor suppressor in breast. Cell Death Differ 15:1752-1759

26. Zhi X, Zhao D, Zhou Z, Liu R, Chen C (2012) YAP promotes breast cell proliferation and survival partially through stabilizing the KLF5 transcription factor. Am J Pathol 180:2452-2461

27. Shen J, Cao B, Wang Y, Ma C, Zeng Z, Liu L et al (2018) Hippo component YAP promotes focal adhesion and tumour aggressiveness via transcriptionally activating THBS1/FAK signalling in breast cancer. J Exp Clin Cancer Res 37:175

28. Kim B, Myung SJ (2018) Clinical implications of the Hippo-YAP pathway in multiple cancer contexts. BMB Rep 51:119-125 
29. Cao L, Sun PL, Yao M, Jia M, Gao H (2017) Expression of YES-associated protein (YAP) and its clinical significance in breast cancer tissues. Hum Pathol 68:166-174

30. Guo L, Teng L (2015) YAP/TAZ for cancer therapy: opportunities and challenges (review). Int J Oncol 46:1444-1452

31. Song R, Gu D, Zhang L, Zhang X, Yu B, Liu B et al (2018 Aug 3) Functional significance of Hippo/YAP signaling for drug resistance in colorectal cancer. Mol Carcinog. https://doi.org/10.1002/mc.22883

32. Liu-Chittenden Y, Huang B, Shim JS, Chen Q, Lee SJ, Anders RA et al (2012) Genetic and pharmacological disruption of the TEAD-YAP complex suppresses the oncogenic activity of YAP. Genes Dev 26:1300-1305

33. Sorrentino G, Ruggeri N, Specchia V, Cordenonsi M, Mano M, Dupont S et al (2014) Metabolic control of YAP and TAZ by the mevalonate pathway. Nat Cell Biol 16:357-366

34. Gronich N, Rennert G (2013) Beyond aspirin-cancer prevention with statins, metformin and bisphosphonates. Nat Rev Clin Oncol 10:625-642

\section{Publisher's Note}

Springer Nature remains neutral with regard to jurisdictional claims in published maps and institutional affiliations.

\section{Submit your manuscript to a SpringerOpen ${ }^{\mathcal{O}}$ journal and benefit from:}

- Convenient online submission

- Rigorous peer review

- Open access: articles freely available online

- High visibility within the field

Retaining the copyright to your article

Submit your next manuscript at $\boldsymbol{\nabla}$ springeropen.com 